\title{
mTOR inhibition reduces growth and adhesion of hepatocellular carcinoma cells in vitro
}

\author{
TOBIAS ENGL ${ }^{1}$, JOCHEN RUTZ ${ }^{1}$, SEBASTIAN MAXEINER ${ }^{1}$, EVA JUENGEL ${ }^{1}$, \\ FREDERIK ROOS $^{1}$, WAEL KHODER ${ }^{1}$, WOLF O. BECHSTEIN ${ }^{1,2}$, KAREN NELSON $^{3}$, \\ IGOR TSAUR $^{1}$, AXEL HAFERKAMP ${ }^{1}$ and ROMAN A. BLAHETA ${ }^{1}$ \\ Departments of ${ }^{1}$ Urology, ${ }^{2}$ General and Visceral Surgery and ${ }^{3}$ Vascular and \\ Endovascular Surgery, Goethe-University, D-60590 Frankfurt am Main, Germany
}

Received August 2,2016; Accepted July 7, 2017

DOI: $10.3892 / \mathrm{mmr} .2017 .7401$

\begin{abstract}
Mechanistic target of rapamycin (mTOR) signaling is typically increased in hepatocellular carcinoma (HCC). A panel of HCC cell lines (HepG2, Hep3B and HuH6) was exposed to various concentrations of the mTOR inhibitors, everolimus and temsirolimus, in order to investigate their effects on cell growth, clonal formation, cell cycle progression, and adhesion and chemotactic migration using MTT and clonal cell growth assays, fluorometric detection of cell cycle phases and a Boyden chamber assay. In addition, integrin $\alpha$ and $\beta$ adhesion receptors were analyzed by flow cytometry and blocking studies using function blocking monoclonal antibodies were conducted to explore functional relevance. The results demonstrated that everolimus and temsirolimus significantly suppressed HCC cell growth and clonal formation, at 0.1 or $1 \mathrm{nM}$ (depending on the cell line). In addition, the number of cells in $G_{0} / G_{1}$ phase was increased in response to drug treatment, whereas the number of $\mathrm{G}_{2} / \mathrm{M}$ phase cells was decreased. Drug treatment also considerably suppressed HCC cell adhesion to immobilized collagen. Integrin profiling revealed strong expression of integrin $\alpha 1, \alpha 2, \alpha 6$ and $\beta 1$ subtypes; and integrin $\alpha 1$ was upregulated in response to mTOR inhibition. Suppression of integrin $\alpha 1$ did not affect cell growth; however, it did significantly decrease adhesion and chemotaxis, with the influence on adhesion being greater than that on motility. Due to a positive association between integrin $\alpha 1$ expression and the extent of adhesion, whereby reduced receptor expression was correlated to decreased cell adhesion, it may be hypothesized that the adhesion-blocking effects of mTOR inhibitors are not associated with mechanical contact inhibition of the $\alpha 1$
\end{abstract}

Correspondence to: Professor Roman A. Blaheta, Department of Urology, Goethe-University, Interdisciplinary Science Building, Building 25A, Room 404, Theodor-Stern-Kai 7, D-60590 Frankfurt am Main, Germany

E-mail: blaheta@em.uni-frankfurt.de

Key words: mechanistic target of rapamycin, hepatocellular carcinoma cells, integrins, adhesion, chemotaxis, proliferation receptor but with integrin $\alpha 1$-dependent suppression of oncogenic signaling, thus preventing tumor cell-matrix interaction.

\section{Introduction}

Hepatocellular carcinoma (HCC) represents the fifth most common type of cancer in males and the ninth most common in females (1). The prognosis of HCC is poor due to the highly aggressive nature of the disease, particularly for HCC patients with recurrent and/or metastatic tumors $(2,3)$.

Increasing knowledge regarding the molecular alterations that initiate malignancy has led to the development of novel compounds targeting pathways aberrantly activated in cancer. Of these, the multiple receptor tyrosine kinase inhibitor sorafenib, which primarily targets platelet-derived growth factor receptor and vascular endothelial growth factor receptor, is the worldwide standard therapy for the treatment of advanced HCC. However, although sorafenib has significantly improved the treatment protocol, the overall response rate is disappointingly low and resistance inevitably develops, further limiting the efficacy of the drug (4).

Recent studies have provided strong evidence to suggest that phosphatidylinositol 3-kinase (PI3K)/Akt/mechanistic target of rapamycin (mTOR) signaling is upregulated in $\mathrm{HCC}$, and activation of this pathway triggers rapid HCC development and progression $(5,6)$. In clinical practice, mTOR hyperactivity has been associated with high-grade tumors and tumors with poor prognosis (7). Therefore, mTOR inhibition may be considered a plausible strategy in mitigating HCC. The present study aimed to investigate the antitumor effects of two mTOR inhibitors, everolimus and temsirolimus. Temsirolimus has been approved for first-line treatment of patients with poor prognosis renal cell carcinoma (RCC), whereas the oral mTOR inhibitor, everolimus, has been recommended for patients with advanced progressive RCC or for patients with failed vascular endothelial growth factor-targeted therapy (8). In the present study, experiments were conducted on a panel of HCC cell lines, and aimed to determine the effects of mTOR inhibitors on tumor growth and invasion. In addition, integrin $\alpha$ and $\beta$ subtype expression was investigated, since these receptors are not only involved in tumor growth and invasion, but also in cellular differentiation. 


\section{Materials and methods}

Cell culture. HepG2 and HuH7 cells were purchased from CLS Cell Lines Service GmbH (Eppelheim, Germany). Hep3B cells were purchased from DSMZ (Braunschweig, Germany). HepG2 cells were grown and subcultured in Dulbecco's modified Eagle's medium:Nutrient Mixture F-12 medium (Thermo Fisher Scientific GmbH, Dreieich, Germany) supplemented with $10 \%$ fetal bovine serum (FBS; Thermo Fisher Scientific $\mathrm{GmbH}), 20 \mathrm{mM}$ Hepes-buffer and gentamicin (0.5 ml/1). HuH7 and Hep3B cells were incubated in RPMI-1640 medium, supplemented with 10\% FBS, 20 mM HEPES-buffer, 1\% glutamax, and $1 \%$ penicillin/streptomycin (all Gibco; Thermo Fisher Scientific $\mathrm{GmbH}$ ) at $37^{\circ} \mathrm{C}$ in a humidified incubator containing $5 \% \mathrm{CO}_{2}$.

mTOR inhibitors. Everolimus (Novartis Pharma AG, Basel, Switzerland) and temsirolimus (LC Laboratories, Woburn, MA, USA) were dissolved in dimethyl sulfoxide (DMSO) as a $10 \mathrm{mM}$ stock solution and stored in aliquots at $-20^{\circ} \mathrm{C}$. Prior to use, the compounds were diluted in cell culture medium. The effects of 0.1-100 nM everolimus or temsirolimus were determined on cell growth to evaluate dose dependency. All further experiments were conducted with $1 \mathrm{nM}$ everolimus or temsirolimus. Cells treated with culture medium alone (supplemented with DMSO, diluted 1:10 $-1: 10^{8}$ ) served as controls. To evaluate the toxic effects of the drugs, following a $72 \mathrm{~h}$ incubation at $37^{\circ} \mathrm{C}$ in a humidified incubator containing $5 \% \mathrm{CO}_{2}$, cell viability was determined by trypan blue staining (Gibco; Thermo Fisher Scientific GmbH). A Zeiss ID 03 light microscope (Zeiss AG, Oberkochen, Germany) was used.

Measurement of tumor cell growth. Cell growth was assessed using the 3-(4,5-dimethylthiazol-2-yl)-2,5-diphenyltetrazolium bromide (MTT) dye reduction assay (Roche Diagnostics GmbH, Penzberg, Germany). HepG2, Hep3B and HuH6 cells, (50 $\mu 1,1 \times 10^{5}$ cells $\left./ \mathrm{ml}\right)$ were seeded onto 96 -well tissue culture plates. After 24,48 and $72 \mathrm{~h}$ incubation at $37^{\circ} \mathrm{C}$ MTT $(0.5 \mathrm{mg} / \mathrm{ml})$ was added for an additional $4 \mathrm{~h}$. Thereafter, cells were lysed in a buffer containing $10 \%$ SDS in $0.01 \mathrm{M} \mathrm{HCl}$. The plates were incubated overnight at $37^{\circ} \mathrm{C}$ in an atmosphere containing $5 \% \mathrm{CO}_{2}$. Absorbance was measured at $550 \mathrm{~nm}$ using a microplate ELISA reader. Each experiment was conducted in triplicate. After subtracting background absorbance, results were expressed as percentage difference, related to a control set to $100 \%$.

Clonogenic growth. HepG2, HuH7, or Hep3B cells, treated with $1 \mathrm{nM}$ everolimus or temsirolimus, were transferred to 6 -well plates at 2,000 cells/well. Following 10 days of incubation, without changing the cell culture medium (everolimus and temsirolimus remained in culture), colonies were fixed with $1 \%$ glutaraldehyde for $10 \mathrm{~min}$ at room temperature and counted. Colonies containing $\geq 50$ cells were counted using a Zeiss ID 03 light microscope (Zeiss AG). Non-treated cells served as controls.

Cell cycle analysis. Cell cycle analysis was performed once the tumor cell cultures had grown to sub-confluency, and after $24 \mathrm{~h}$ of drug treatment. Tumor cell populations were stained with propidium iodide using a Cycleyest Plus DNA Reagent kit (BD Biosciences, Heidelberg, Germany) and were then subjected to flow cytometry using a FACScan flow cytometer (BD Biosciences). A total of 10,000 events were collected for each sample. Data acquisition was conducted using CellQuest version 6.0 software (BD Biosciences) and cell cycle distribution was calculated using ModFit version 3.0 software (BD Biosciences). The number of gated cells in the $\mathrm{G}_{1^{-}}, \mathrm{S}-$, or $\mathrm{G}_{2} / \mathrm{M}$-phases was expressed as a percentage of the total cell population.

Western blot analysis. To investigate the expression levels of cell cycle-regulating proteins, tumor cell lysates $(50 \mu \mathrm{g}$; protein concentration was quantified by Bradford assay) were loaded onto a $7 \%$ polyacrylamide gel and were electrophoresed for $90 \mathrm{~min}$ at $100 \mathrm{~V}$. The lysis buffer consisted of Tris-NaCl, 10\% Tergitol, $0.25 \%$ Na-deoxycholate, $1 \mathrm{mM}$ EDTA, $1 \mathrm{mg} / \mathrm{ml}$ aprotinin, $1 \mathrm{mg} / \mathrm{ml}$ leupeptin, $1 \mathrm{mg} / \mathrm{ml}$ pepstatin, $2 \mathrm{mM} \mathrm{NaF}, 2 \mathrm{mM}$ $\mathrm{Na}_{3} \mathrm{VO}_{4}$ and $2 \mathrm{mM}$ PMSF. Protein was then transferred to nitrocellulose membranes for $1 \mathrm{~h}$ at $100 \mathrm{~V}$. After blocking with non-fat dry milk for $1 \mathrm{~h}$ at room temperature, the membranes were incubated overnight at $4^{\circ} \mathrm{C}$ with monoclonal antibodies directed against the following cell cycle-associated proteins: Phosphorylated (p)-Akt [clone 104A282, mouse immunoglobulin (Ig)G1; dilution 1:500; cat. no. 550747; BD Biosciences], p-mTOR (clone D9C2; IgG, Ser2448; dilution 1:1,000; cat. no. 5536S) and p-Raptor (IgG, Ser792; dilution 1:1,000; cat. no. 2083S; all Cell Signaling Technology Europe, B.V., Leiden, The Netherlands). Horseradish peroxidase-conjugated goat-anti-mouse IgG (dilution, 1:5,000; cat. no. 161-0380; Bio-Rad Laboratories, Inc., Hercules, CA, USA) served as the secondary antibody (30 min incubation at room temperature). The membranes were briefly incubated at room temperature with an enhanced chemiluminescence (ECL) detection reagent $\left(\mathrm{ECL}^{\mathrm{TM}}\right.$; Merck KGaA, Darmstadt, Germany; cat. no. WBKLS0100) to visualize the proteins and were then analyzed using the Fusion FX7 system (Peqlab Biotechnologie GmbH, Erlangen, Germany). $\beta$-actin (1:1,000; cat. no. A5441; Sigma-Aldrich; Merck KGaA) served as an internal control.

Tumor cell adhesion assay. For the tumor cell adhesion assay, 6 -well plates were coated with collagen $\mathrm{G}$ (extracted from calfskin, consisting of $90 \%$ collagen type I and $10 \%$ collagen type III; diluted to $400 \mu \mathrm{g} / \mathrm{ml}$ in PBS; Thermo Fisher Scientific $\mathrm{GmbH}$ ) overnight. Plastic dishes served as the background control. Plates were washed with $1 \%$ bovine serum albumin (BSA; Sigma Aldrich; Merck KGaA) in PBS to block nonspecific cell adhesion. HCC tumor cells $\left(0.5 \times 10^{6}\right)$ were then added to each well for $60 \mathrm{~min}$. Subsequently, non-adherent tumor cells were washed off, and the remaining adherent cells were fixed for $10 \mathrm{~min}$ at room temperature with $1 \%$ glutaraldehyde and counted under a Zeiss ID 03 light microscope (Zeiss AG). Mean cellular adhesion, defined as adherent cells $_{\text {coated well }}$-adherent cells $_{\text {background }}$, was calculated from five different observation fields $\left(5 \times 0.25 \mathrm{~mm}^{2}\right)$.

Tumor cell chemotaxis. Serum-induced chemotaxis was investigated using 6-well Transwell chambers (Greiner Bio-One $\mathrm{GmbH}$, Frickenhausen, Germany) with $8-\mu \mathrm{m}$ pores. HCC tumor cells $\left(0.5 \times 10^{6} / \mathrm{ml}\right)$ were placed in the upper chamber in 
serum-free medium. The lower chamber contained complete cell culture medium including 10\% serum (Sigma Aldrich; Merck KGaA). After $20 \mathrm{~h}$ at $37^{\circ} \mathrm{C}$, the upper surface of the Transwell membrane was gently wiped with a cotton swab to remove cells that had not migrated. Cells that had moved to the lower surface of the membrane were stained using hematoxylin and counted under a light microscope (Zeiss ID 03; Zeiss AG). Mean chemotaxis was calculated from five different observation fields $\left(5 \times 0.25 \mathrm{~mm}^{2}\right)$.

Integrin surface expression. HepG2, HuH7 or Hep3B cells were detached from their culture flasks by Accutase (PAA Laboratories; GE Healthcare) and washed in blocking solution (PBS, $0.5 \%$ BSA). Cells were then incubated for $60 \mathrm{~min}$ at $4^{\circ} \mathrm{C}$ with phycoerythrin (PE)-conjugated monoclonal antibodies (mAbs) directed against the following integrin subtypes: Anti- $\alpha 1$ (mouse IgG1, clone SR84; cat. no. 742362), anti- $\alpha 2$ (mouse IgG2a, clone $12 \mathrm{~F} 1$; cat. no. 555669), anti- $\alpha 3$ (mouse IgG1, clone C3 II.1; cat. no. 746157), anti- $\alpha 4$ (mouse IgG1, clone 9F10; cat. no. 658332), anti- $\alpha 5$ (mouse IgG1, clone IIA1; cat. no. 555615), anti- $\alpha 6$ (rat IgG2a, clone GoH3; cat. no. 555734), anti- $\beta 1$ (mouse IgG1, clone MAR4; cat. no. 557332), anti- $\beta 3$ (mouse IgG1, clone VI-PL2; cat. no. 555752), and anti- $\beta 4$ (rat IgG2a; clone 439-9B; cat. no. 555720; all $20 \mu \mathrm{l} /$ test; using the manufacturing dilution; all BD Biosciences). Tumor cell integrin expression was then measured using a FACScan [BD Biosciences; FL-2H (log) channel histogram analysis; $1 \times 10^{4}$ cells per scan] and was expressed as mean fluorescence units. A mouse IgG1-PE (MOPC-21) or IgG2a-PE (G155-178) (BD Biosciences) was used as an isotype control.

Integrin suppression. To determine whether integrin $\alpha 1$ impacts tumor growth, HepG2 cells were incubated for $60 \mathrm{~min}$ at $37^{\circ} \mathrm{C}$ with $10 \mu \mathrm{g} / \mathrm{ml}$ function-blocking anti-integrin $\alpha 1$ (clone FB12) mAb (Merck KGaA; cat. no. MAB1973Z). Controls were incubated with cell culture medium alone. Subsequently, tumor cell growth was analyzed using the MTT assay, as aforementioned. To evaluate whether integrin $\alpha 1$ acts on tumor cell motility, adhesion and migration experiments were conducted using HepG2 cells following integrin $\alpha 1$ suppression. To evaluate tumor cell binding to matrix proteins, 24-well plates coated with fibronectin (BD Biosciences) were used. Plastic dishes served as the background control. Plates were washed with $1 \%$ BSA in PBS to block nonspecific cell adhesion. Subsequently, $0.5 \times 10^{6}$ tumor cells were added to each well and incubated for $60 \mathrm{~min}$ at $37^{\circ} \mathrm{C}$. Non-adherent tumor cells were washed off and the remaining adherent cells were fixed with $1 \%$ glutaraldehyde for $10 \mathrm{~min}$ at room temperature and counted by a light microscope (Zeiss ID 03; Zeiss AG). The mean cellular adhesion rate, defined as adherent cells $\mathrm{s}_{\text {coated well }}$-adherent cells $\mathrm{background}_{\text {, was calculated from five }}$ different observation fields. To evaluate tumor cell migration, serum-induced chemotaxis was examined using 6-well Transwell chambers (Greiner Bio-One $\mathrm{GmbH}$ ) with $8-\mu$ m pores preformed as described above (Tumor cell chemotaxis subsection), however, only $0.5 \times 10^{6}$ HepG2 cells were applied.

Statistical analysis. Statistical analysis was performed using BiAS software version 11.06 (http://www.bias-online.de/). All experiments were performed between three and six times. Data are presented as the mean \pm standard deviation. Statistical significance between groups was determined using the Mann-Whitney $\mathrm{U}$ test. $\mathrm{P}<0.05$ was considered to indicate a statistically significant difference.

\section{Results}

Exposure to everolimus or temsirolimus reduces HCC cell growth. Ascending concentrations of everolimus or temsirolimus induced a dose-dependent significant reduction in the number of HCC cells. Everolimus exerted a growth inhibitory effect at $0.1 \mathrm{nM}$ in Hep3B and HuH7 cells, where temsirolimus exerted an inhibitory effect at $1 \mathrm{nM}$ in HepG2 and HuH7 cells; the most obvious effect was apparent at $100 \mathrm{nM}$ compared with the untreated controls (Fig. 1). No signs of toxicity were apparent, as determined by a trypan blue exclusion assay (data not shown).

Clonogenic growth was significantly reduced when all three tumor cell lines were treated with $1 \mathrm{nM}$ everolimus or temsirolimus (Fig. 2A-C). In addition, everolimus (1 $\mathrm{nM}$ ) and temsirolimus $(1 \mathrm{nM})$ modulated cell cycle progression. The number of HepG2 cells in the $\mathrm{G}_{2} / \mathrm{M}$ - and S-phases was reduced, whereas the number of tumor cells in the $\mathrm{G}_{0} / \mathrm{G} 1$-phase was increased compared with the controls (Fig. 2D).

Since everolimus and temsirolimus target the mTOR signaling pathway, the Akt-mTOR axis was also evaluated. p-mTOR and p-Raptor expression was suppressed following treatment of all cell lines with both compounds (Fig. 2E). However, as total protein content was not detected in the present study, the activation status of the proteins cannot be confirmed. In addition, p-Akt expression was reduced in the HepG2 and Hep3B cell lines, but was undetectable in $\mathrm{HuH} 7$ cells.

Everolimus and temsirolimus modify integrin al expression. The integrin subtypes $\alpha 1, \alpha 2, \alpha 6$ and $\beta 1$ were strongly expressed on HepG 2 cells, whereas $\alpha 3, \alpha 4, \alpha 5, \beta 3$ and $\beta 4$ were not detected (Fig. 3A). Integrin expression was also detected on $\mathrm{Hep} 3 \mathrm{~B}$ and $\mathrm{HuH} 7$ cells; it was demonstrated that $\alpha 1, \alpha 2, \alpha 6$ and $\beta 1$ were expressed on these cell lines (Fig. 3B). Treatment of HepG2 cells with everolimus or temsirolimus significantly elevated the expression of integrin $\alpha 1$ on the tumor cell surface, without acting on $\alpha 2, \alpha 6$ or $\beta 1$ expression (Fig. 3C).

Everolimus and temsirolimus suppress HCC cell adhesion but not migration. Treatment with everolimus or temsirolimus (1 nM) significantly downregulated adhesion of HepG2, HuH7 and Hep3B cells to immobilized collagen (Fig. 4A). The most prominent effects were evoked in HepG2 and Hep3B cells. Control values were $61.4 \pm 11.2$ cells $/ \mathrm{mm}^{2}$ (HepG2), $66.8 \pm 14.2$ cells $/ \mathrm{mm}^{2}(\mathrm{HuH7})$ and $79.4 \pm 14.8$ cells $/ \mathrm{mm}^{2}$ (Hep3B). A chemotaxis assay revealed that HepG2 and Hep3B motility was enhanced following exposure to temsirolimus or everolimus exposure (Fig. 4B). However, the control values were low (HepG2: $16.2 \pm 4.2$ cells $/ \mathrm{mm}^{2}$, Hep3B: $6.8 \pm 3.5$ cells $/ \mathrm{mm}^{2}$ ). $\mathrm{HuH7}$ cells did not migrate through the filter membrane.

Integrin $\alpha 1$ suppression. Since everolimus and temsirolimus induced a distinct upregulation in integrin $\alpha 1$ on HepG2 cells, subsequent experiments aimed to determine the functional 

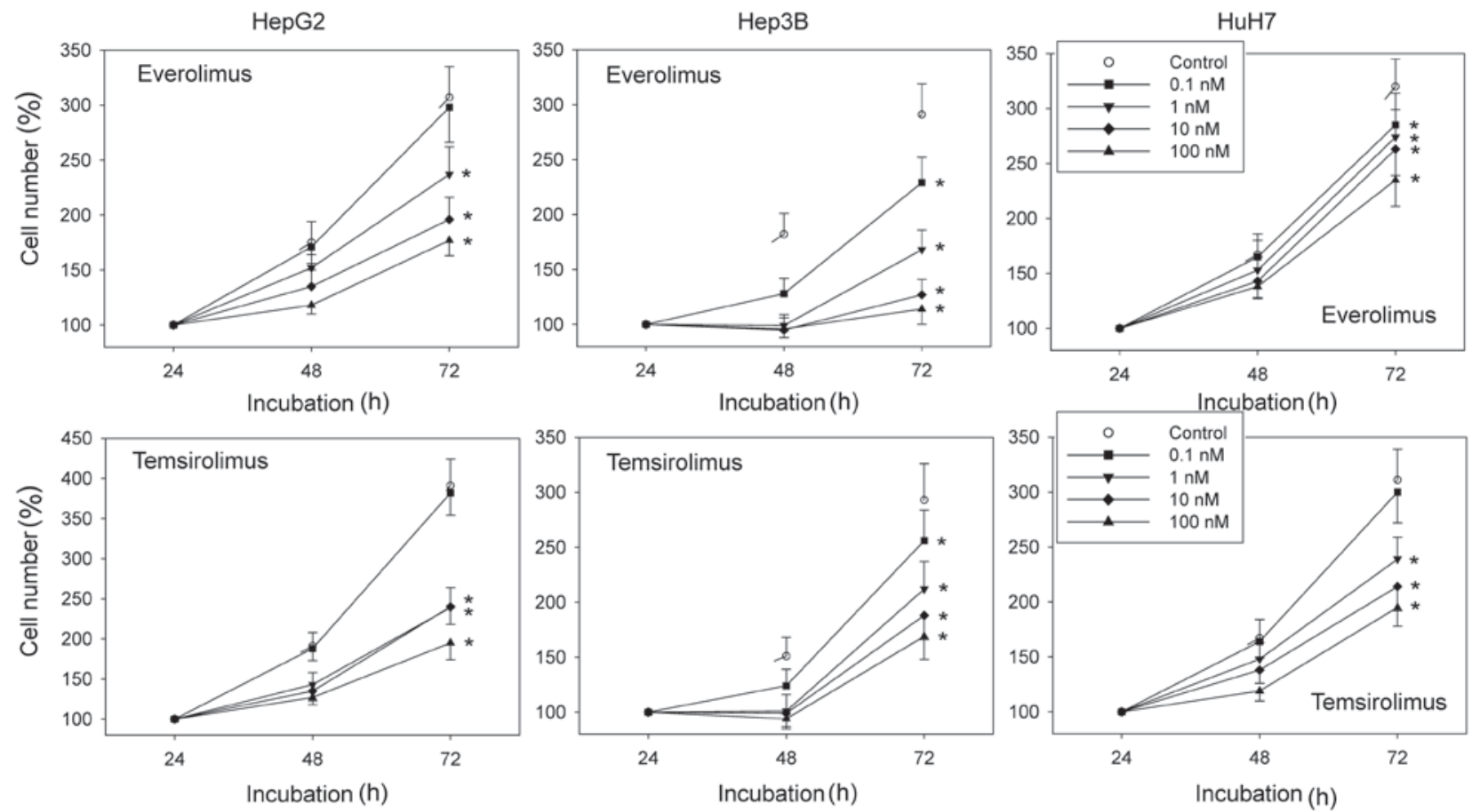

Figure 1. Growth inhibitory effects of everolimus or temsirolimus on HepG2, Hep3B and HuH7 cells at 24-72 h. The results of one of the six independent experiments performed are presented. ${ }^{\mathrm{P}}<0.05$ vs. the control group, set to $100 \%(\mathrm{n}=6)$.
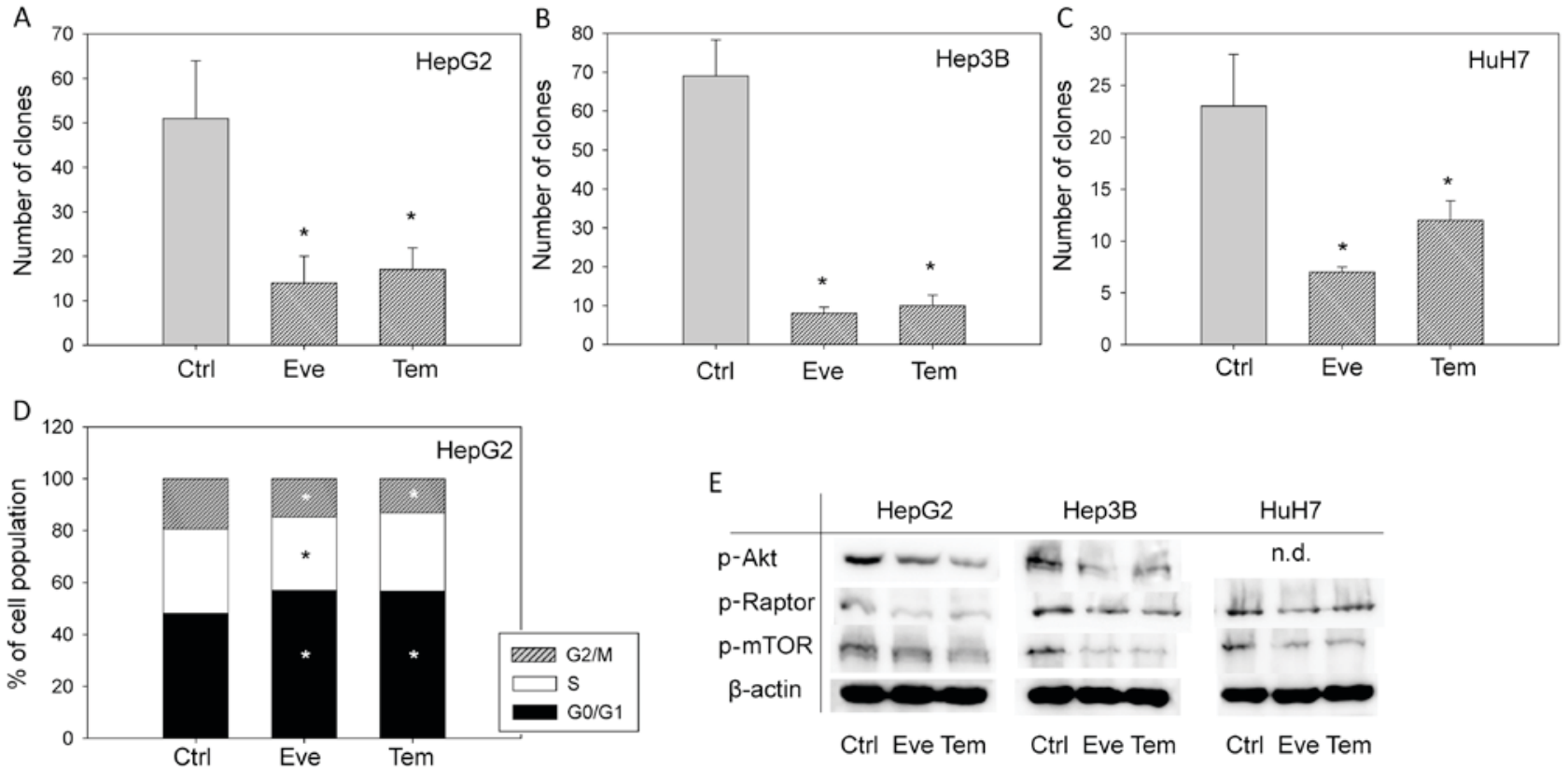

Figure 2. Clonogenic growth of (A) HepG2, (B) Hep3B and (C) HuH7 cells with or without Eve or Tem treatment for 10 days. (D) Cell cycle analysis of HepG2 cells after $24 \mathrm{~h}$ Eve or Tem exposure compared with the Ctrl cells. The proportion of cells in each phase is expressed as a percentage of total cells. Experiments were conducted in triplicate and repeated five times. ${ }^{*} \mathrm{P}<0.05$ vs. the Ctrl group. (E) Western blot analysis of mTOR-associated proteins in HepG2, Hep3B and $\mathrm{HuH} 7$ cells. $\beta$-actin served as an internal control. A representative image of three independent experiments is presented. Ctrl, control; Eve, everolimus; mTOR, mechanistic target of rapamycin; n.d., not detected; p-phosphorylated; Tem, temsirolimus.

relevance of this receptor. Suppression of integrin $\alpha 1$ slightly decreased HepG2 cell growth; however, this was not significant (Fig. 4C). The strongest effects were observed with respect to tumor cell adhesion, which was reduced by $>40 \%$ following integrin $\alpha 1$ suppression (Fig. 4D). Chemotactic activity was also significantly decreased in the presence of anti-integrin $\alpha 1$ compared with the control group (30\% decrease; Fig. 4D).

\section{Discussion}

Better understanding of tumor cell biology has led to the development of numerous targeted therapeutic agents. The $\mathrm{PI} 3 \mathrm{~K} / \mathrm{Akt} / \mathrm{mTOR}$ pathway has been identified as a pivotal key regulator of cell growth, cell proliferation and cell survival. Targeting the mTOR pathway has, therefore, been proposed 
A
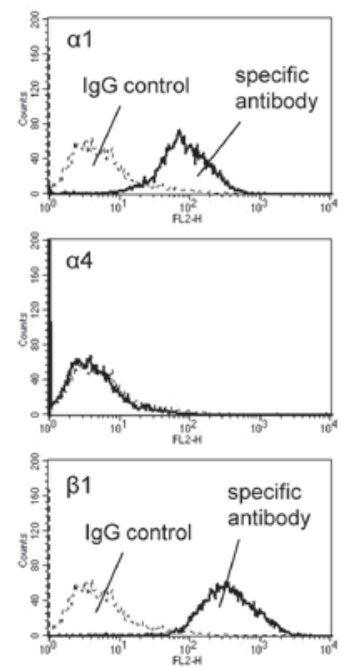

Integrin expression profile - HepG2



\begin{tabular}{l|ccc} 
& HepG2 & HUH7 & Hep3B \\
\hline Integrin a1 & 99.5 & 37.9 & 114.2 \\
Integrin a2 & 438.4 & 79.5 & 131.9 \\
Integrin a6 & 137.1 & 105.8 & 60.5 \\
Integrin $\beta 1$ & 576.9 & 386.2 & 298.0 \\
& & \\
$\mathrm{SD}_{\text {intra-assay }}<10 \%$ & & \\
$\mathrm{SD}_{\text {inter-assay }}<25 \%$ &
\end{tabular}

C

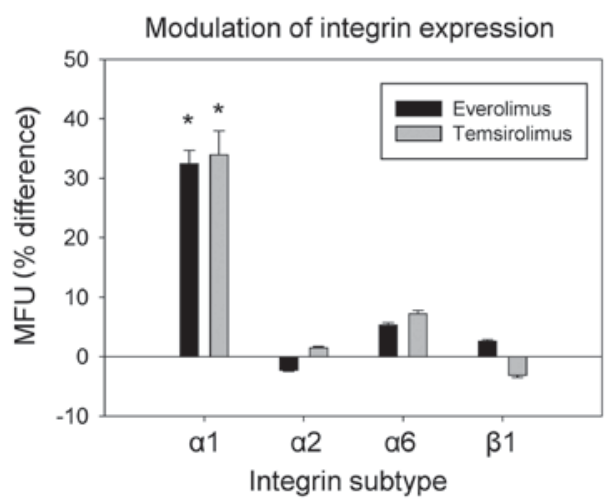

Figure 3. (A) Integrin expression in untreated HCC cells. The dotted line indicates background fluorescence (IgG control) and the solid line indicates specific fluorescence (specific antibody). (B) Comparative analysis of integrin subtype expression on HepG2, Hep3B and HuH7 cells. (C) Integrin subtype expression on HepG2 cells following $24 \mathrm{~h}$ exposure to everolimus or temsirolimus, compared with untreated controls set at $100 \%$. "P<0.05 vs. the control group. IgG, immunoglobulin G; MFU, mean fluorescent units; SD, standard deviation.

as an innovative strategy to treat cancer, and mTOR inhibitors have been approved for RCC treatment. However, the clinical relevance of mTOR inhibition in treating HCC remains unclear. Everolimus has been reported to delay tumor progression in patients with sorafenib-refractory HCC (9); however, a recent investigation did not demonstrate improved patient survival in a second-line setting or in sorafenib-intolerant patients (10). Yeo et al (11) and Cho et al (12) hypothesized that only selected patients, depending on the expression of relevant target proteins, may benefit from an mTOR-based treatment regimen. The benefit of an everolimus-sorafenib combination is controversial, since although a dose-finding study on patients with advanced HCC yielded encouraging results (13), a randomized multicenter, multinational phase II trial did not indicate a synergistic effect (14).

The present study demonstrated the growth inhibitory effects of everolimus and temsirolimus on numerous HCC cell lines; these agents exhibited effects at 0.1 or $1 \mathrm{nM}$, respectively. The effects observed may, at least in part, be induced by the downregulation of p-mTOR and particularly p-Raptor. Notably, p-Akt was not detected in HUH7, which indicates that this cell type may be associated with an Akt independent pathway with very low (undetectable) Akt activity or a less sensitive antibody may have been used in the present study.

In accordance with the present study, HepG2 cells have been reported to respond to $1 \mathrm{nM}$ everolimus in vitro (15). In addition, the half maximal inhibitory concentration values of everolimus or temsirolimus in HepG2 cells have been reported to range between $0.9 \mathrm{nM}(16)$ and $9 \mu \mathrm{M}$ (17). Similar sensitivity to mTOR inhibition has been reported for Hep3B and HuH7 cells $(18,19)$, indicating that mTOR inhibition may be of clinical relevance in treating HCC. When discussing the behavior of the cell lines used in the present study, it must be emphasized that HepG2 cells were isolated from a liver biopsy with primary hepatoblastoma and HCC characteristics (20). Although HepG2 cells possess tumor-specific characteristics, they do not form tumors when injected into athymic mice and are histologically similar to the hepatoblastoma from which the cell line was derived (20). Therefore, HepG2 should be considered a hepatoblastoma, rather than a carcinoma, cell line.

Based on the results of a cell cycle analysis, cell growth inhibition in the presence of everolimus and temsirolimus may be caused by driving the tumor cells from $\mathrm{G}_{2} / \mathrm{M}$ - and S-phases into $G_{0} / G_{1}$. The differences between the number of $\mathrm{G}_{2} / \mathrm{M}$ - and S-phase cells in the treated and non-treated tumor cells were moderate; however, similar moderate differences have also recently been observed, when HepG2 cells were exposed to the mTOR inhibitor sirolimus. Suppression of tumor cell proliferation by this drug was also associated with only a moderate $G_{0} / G_{1}$ increase and S-phase decrease (21). In addition, it has been speculated that a $G_{0} / G_{1}$ phase arrest, but not apoptosis, may be the predominant mechanism responsible for the antiproliferative activity of sirolimus (22). Everolimus has been reported to suppress cyclins A, B1 and D1 in an in vivo HCC xenograft model (22). Although the role of these cyclins in cell cycle progression has yet to be elucidated in detail, there is evidence that loss of cyclin A, B1 and/or D1 may at least partially contribute to $\mathrm{HCC}$ cell accumulation in $\mathrm{G}_{0} / \mathrm{G}_{1}$-phase $(23,24)$. Notably, exposing Hep3B and HuH7 cells to everolimus also induced a $\mathrm{G}_{0} / \mathrm{G}_{1}$-phase arrest, indicating a common mechanism for this class of drugs (15). 
A

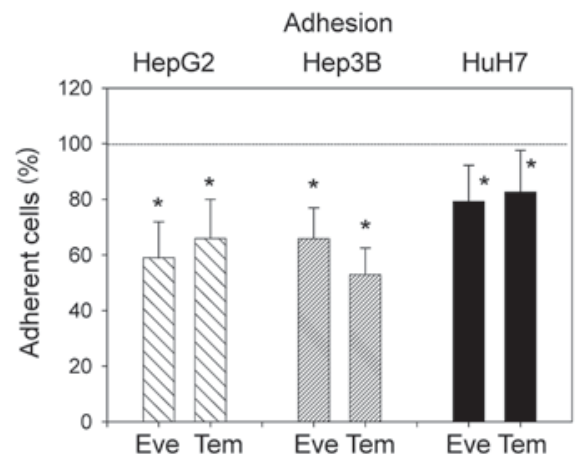

C

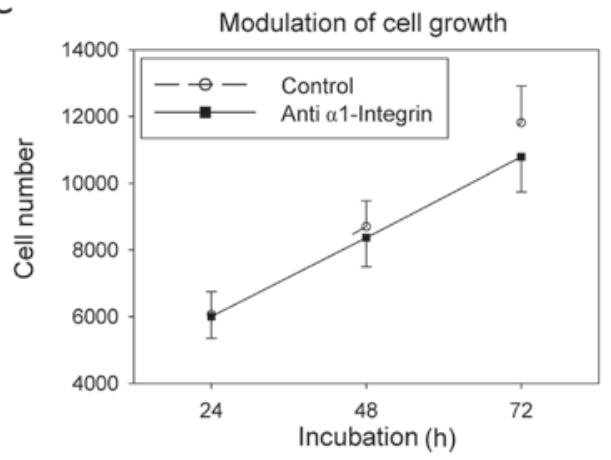

B

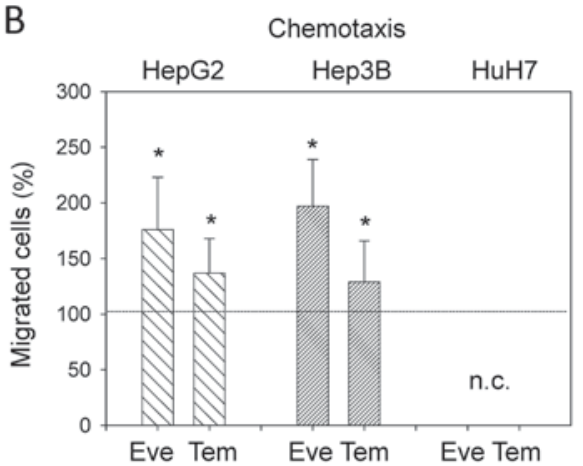

D

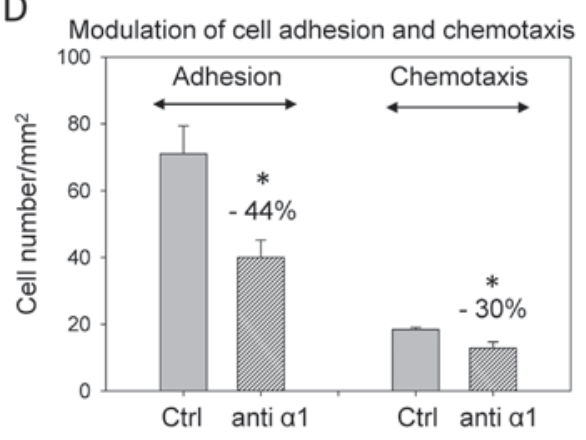

Figure 4. Effects of Eve or Tem on (A) adhesion to immobilized collagen and (B) chemotaxis of HepG2, Hep3B and HuH7 cells. Chemotaxis was assessed using a Transwell chamber assay. (A and B) Mean values from five experiments are presented compared to the untreated Ctrl cells (cell culture medium supplemented with dimethyl sulfoxide, diluted $1: 10^{7}$ ) set at $100 \%$. $^{*} \mathrm{P}<0.05$ vs. the Ctrl group. (C) Effects of integrin $\alpha 1$ suppression on HepG2 cell growth. (D) Effects of integrin $\alpha 1$ suppression on HepG2 cell adhesion and chemotaxis. Tumor cells were preincubated for 60 min with a function-blocking anti-integrin $\alpha 1$ antibody. Ctrl cells were untreated $\left(0.25 \mathrm{M} \mathrm{NaCl}\right.$ containing $0.1 \%$ sodium azide, diluted $1: 100$ in cell culture medium). ${ }^{*} \mathrm{P}<0.05 \mathrm{vs}$. the $\mathrm{Ctrl}$ group ( $\left.\mathrm{n}=6\right)$. Ctrl, control; Eve, everolimus; Tem, temsirolimus.

Suppression of adhesion by everolimus and temsirolimus was determined in the present study. Maximum effects were exerted on HepG 2 and Hep3B cells, with a $>40$ and 50\% reduction, respectively. This is important, since tumor cell-matrix interaction is critical for malignant tumor progression and metastatic spreading. The results of the chemotaxis assay are difficult to interpret in this context, since the percentage of migrating cells increased in the presence of mTOR inhibitors. However, it must be noted that only a few cells migrated across the filter membrane in the control group. Therefore, slight differences in the absolute number of motile cells following everolimus or temsirolimus treatment are associated with large percentage changes. An elevation of just 3 single Hep3B cells following treatment was associated with a percentage difference $>40 \%$ compared with the control group. Whether the moderate elevation in cell migration, based on absolute cell number count, is clinically relevant or unspecific remains to be elucidated. Based on a wound-healing assay, the motility of HepG2, HuH7 and Hep3B cells has recently been reported to be significantly reduced by everolimus, whereas a Transwell migration assay, which was conducted in parallel, demonstrated a slight elevation in HepG2 and HuH7 migration (18). These data suggested a partial assay-dependent effect. To determine the effects of mTOR inhibitors on tumor cell migration, further investigation is required. Since everolimus and temsirolimus markedly suppressed HCC cell adhesion in the present in vitro model, it is hypothesized that this property is the dominant mechanism underlying the effects of these compounds.
Integrins serve a significant role in tumorigenesis and progression, including tumor growth, adhesion and invasion. The integrin profile analysis conducted in the present study detected a strong surface expression of the $\alpha 1, \alpha 2, \alpha 6$, and $\beta 1$ integrin subtypes. Integrin $\alpha 5$ was not detected on HepG2 cells, which is contradictory to the findings of an earlier study, which revealed a moderate integrin $\alpha 5$ surface level on HepG2 cells (24). However, in the previous investigation, integrin $\alpha 5$ was not detected by western blotting, thus suggesting that integrin $\alpha 5$ does not serve a crucial role in HepG2 cell behavior. In the present study, integrin $\alpha 1$ was the only integrin significantly increased in response to everolimus or temsirolimus treatment. The relevance of this increase is not yet clear. Based on integrin blocking studies, integrin $\alpha 1$ does not appear involved in cell growth regulation. However, suppression of integrin $\alpha 1$ was strongly associated with reduced adhesion and migration, with a stronger effect on adhesion.

The role of integrin $\alpha 1$ in HCC metastasis is currently unclear. Liu et al (25) detected a positive correlation between integrin $\alpha 1$ and migration and invasion, which is in accordance with the present study. However, compared with the present investigation, adhesion assays were not conducted. The integrin-blocking model used in the present study explored the mechanical contact of $\alpha 1$ to its substrate. Since everolimus- or temsirolimus-induced suppression of HCC cell adhesion was accompanied by elevated integrin $\alpha 1$ expression, the positive association between $\alpha 1$ and migration cannot be transferred to the adhesion process. Another mode of action must, therefore, be assumed, which is not associated with mechanical contact inhibition of $\alpha 1$ and its receptor 
in the collagen matrix. Notably, previous studies have indicated that integrin $\alpha 1$ may indirectly influence HCC progression by deactivating oncogenic signaling $(26,27)$. Chen et al (28) hypothesized that integrin $\alpha 1$ may initiate mesenchymal to epithelial transition, with a high expression level associated with a low tumor cell adhesion capacity. This scenario may also hold true in the present model system, where this particular integrin may control cellular re-differentiation, leading to a less adhesive phenotype. However, this hypothesis is speculative and requires further confirmation. In addition, integrin $\alpha 1$ expression has been reported to be reduced in patients with metastatic breast cancer (29), and a high integrin $\alpha 1$ level has been revealed to correlate with a beneficial therapeutic response in a patient with melanoma (30).

In conclusion, in the present study, the in vitro malignancy of HCC was reduced following treatment with the mTOR inhibitors, everolimus and temsirolimus, thus indicating that the mTOR pathway may be a potential target in the treatment of HCC. Both drugs suppressed HCC cell growth and adhesion, and were demonstrated to regulate integrin $\alpha 1$ expression, which is a novel finding. In addition, tumor-matrix interaction was blocked and, consequently, migration may decrease. However, the effects of mTOR inhibitors on invasive processes require further evaluation. At present, clinical reports remain ambivalent regarding the value of mTOR inhibition $(31,32)$. Possibly, identification of a predictive biomarker may aid in selecting patients most likely to respond to everolimus or temsirolimus. In addition to optimizing the mTOR inhibitor-based protocol, which includes dual targeting of the mTOR complexes (mTORCs), mTORC1 and mTORC2 $(18,33)$, further studies should focus on combination strategies that interfere not only with the mTOR signaling cascade, but with different tumor targets.

\section{References}

1. Ferlay J, Soerjomataram I, Dikshit R, Eser S, Mathers C, Rebelo M, Parkin DM, Forman D and Bray F: Cancer incidence and mortality worldwide: Sources, methods and major patterns in GLOBOCAN 2012. Int J Cancer 136: E359-E386, 2015.

2. Llovet JM, Ricci S, Mazzaferro V, Hilgard P, Gane E, Blanc JF, de Oliveira AC, Santoro A, Raoul JL, Forner A, et al: Sorafenib in advanced hepatocellular carcinoma. N Engl J Med 359: 378-390, 2008

3. Cheng AL, Kang YK, Chen Z, Tsao CJ, Qin S, Kim JS, Luo R, Feng J, Ye S, Yang TS, et al: Efficacy and safety of sorafenib in patients in the Asia-Pacific region with advanced hepatocellular carcinoma: A phase III randomised, double-blind, placebo-controlled trial. Lancet Oncol 10: 25-34, 2009.

4. Abou-Alfa GK, Schwartz L, Ricci S, Amadori D, Santoro A, Figer A, De Greve J, Douillard JY, Lathia C, Schwartz B, et al: Phase II study of sorafenib in patients with advanced hepatocellular carcinoma. J Clin Oncol 24: 4293-4300, 2006.

5. Hu J, Che L, Li L, Pilo MG, Cigliano A, Ribback S, Li X, Latte G, Mela M, Evert M, et al: Co-activation of AKT and c-Met triggers rapid hepatocellular carcinoma development via the mTORC1/FASN pathway in mice. Sci Rep 6: 20484, 2016.

6. Ewald F, Nörz D, Grottke A, Bach J, Herzberger C, Hofmann BT, Nashan B and Jücker M: Vertical targeting of AKT and mTOR as well as dual targeting of AKT and MEK signaling is synergistic in hepatocellular carcinoma. J Cancer 6: 1195-1205, 2015.

7. Zhou L, Huang Y, Li J and Wang Z: The mTOR pathway is associated with the poor prognosis of human hepatocellular carcinoma. Med Oncol 27: 255-261, 2010.

8. Najjar YG and Rini BI: Novel agents in renal carcinoma: A reality check. Ther Adv Med Oncol 4: 183-194, 2012.

9. Zhu AX, Abrams TA, Miksad R, Blaszkowsky LS, Meyerhardt JA, Zheng H, Muzikansky A, Clark JW, Kwak EL, Schrag D, et al: Phase $1 / 2$ study of everolimus in advanced hepatocellular carcinoma. Cancer 117: 5094-5102, 2011
10. Zhu AX, Kudo M, Assenat E, Cattan S, Kang YK, Lim HY, Poon RT, Blanc JF, Vogel A, Chen CL, et al: Effect of everolimus on survival in advanced hepatocellular carcinoma after failure of sorafenib: The EVOLVE-1 randomized clinical trial. JAMA 312: 57-67, 2014.

11. Yeo W, Chan SL, Mo FK, Chu CM, Hui JW, Tong JH, Chan AW, Koh J, Hui EP, Loong H, et al: Phase I/II study of temsirolimus for patients with unresectable Hepatocellular Carcinoma (HCC)a correlative study to explore potential biomarkers for response. BMC Cancer 15: 395, 2015.

12. Cho J, Lee J, Kim J, Kim ST, Lee S, Kim SY, Ha SY, Park CK and Lim HY: Loss of tuberous sclerosis complex 2 (TSC2) as a predictive biomarker of response to mTOR inhibitor treatment in patients with hepatocellular carcinoma. Transl Oncol 9: 466-471, 2016.

13. Kelley RK, Nimeiri HS, Munster PN, Vergo MT, Huang Y,Li CM, Hwang J, Mulcahy MF, Yeh BM, Kuhn P, et al: Temsirolimus combined with sorafenib in hepatocellular carcinoma: A phase I dose-finding trial with pharmacokinetic and biomarker correlates. Ann Oncol 24: 1900-1907, 2013.

14. Koeberle D, Dufour JF, Demeter G, Li Q, Ribi K, Samaras P, Saletti P, Roth AD, Horber D, Buehlmann M, et al: Sorafenib with or without everolimus in patients with advanced hepatocellular carcinoma (HCC): A randomized multicenter, multinational phase II trial (SAKK $77 / 08$ and SASL 29). Ann Oncol 27: 856-861, 2016.

15. Grabinski N, Ewald F, Hofmann BT, Staufer K, Schumacher U, Nashan B and Jücker M: Combined targeting of AKT and mTOR synergistically inhibits proliferation of hepatocellular carcinoma cells. Mol Cancer 11: 85, 2012.

16. Zhou Q, Wong CH, Lau CP, Hui CW, Lui VW, Chan SL and Yeo W: Enhanced antitumor activity with combining effect of mTOR inhibition and microtubule stabilization in hepatocellular carcinoma. Int J Hepatol 2013: 103830, 2013.

17. Zhou Q, Lui VW, Lau CP, Cheng SH, Ng MH, Cai Y, Chan SL and Yeo W: Sustained antitumor activity by co-targeting mTOR and the microtubule with temsirolimus/vinblastine combination in hepatocellular carcinoma. Biochem Pharmacol 83: 1146-1158, 2012.

18. Kim JO, Kim KH, Song IS, Cheon KS, Kim OH, Lee SC, Lee SK and Kim SJ: Potentiation of the anticancer effects of everolimus using a dual mTORC1/2 inhibitor in hepatocellular carcinoma cells. Oncotarget 8: 2936-2948, 2017.

19. Chan SL, Wong CH, Lau CP, Zhou Q, Hui CW, Lui VW, Ma BB, Chan AT and Yeo W: Preclinical evaluation of combined TKI-258 and RAD001 in hepatocellular carcinoma. Cancer Chemother Pharmacol 71: 1417-1425, 2013.

20. Aden DP, Fogel A, Plotkin S, Damjanov I and Knowles BB: Controlled synthesis of HBsAg in a differentiated human liver carcinoma-derived cell line. Nature 282: 615-616, 1979.

21. Pivonello C, Negri M, De Martino MC, Napolitano M, de Angelis C, Provvisiero DP, Cuomo G, Auriemma RS, Simeoli C, Izzo F, et al: The dual targeting of insulin and insulin-like growth factor 1 receptor enhances the mTOR inhibitor-mediated antitumor efficacy in hepatocellular carcinoma. Oncotarget 7: 9718-9731, 2016.

22. Kirstein MM, Boukouris AE, Pothiraju D, Buitrago-Molina LE, Marhenke S, Schütt J, Orlik J, Kühnel F, Hegermann J, Manns MP, et al: Activity of the mTOR inhibitor RAD001, the dual mTOR and PI3-kinase inhibitor BEZ235 and the PI3-kinase inhibitor BKM120 in hepatocellular carcinoma. Liver Int 33: 780-793, 2013.

23. Gao Y, Lin LP, Zhu CH, Chen Y, Hou YT and Ding J: Growth arrest induced by $\mathrm{C} 75$, A fatty acid synthase inhibitor, was partially modulated by $\mathrm{p} 38$ MAPK but not by $\mathrm{p} 53$ in human hepatocellular carcinoma. Cancer Biol Ther 5: 978-985, 2006.

24. Gnainsky Y, Spira G, Paizi M, Bruck R, Nagler A, Genina O, Taub R, Halevy $\mathrm{O}$ and Pines $\mathrm{M}$ : Involvement of the tyrosine phosphatase early gene of liver regeneration (PRL-1) in cell cycle and in liver regeneration and fibrosis effect of halofuginone. Cell Tissue Res 324: 385-394, 2006.

25. Liu X, Tian H, Li H, Ge C, Zhao F, Yao M and Li J: Derivate isocorydine (d-ICD) suppresses migration and invasion of hepatocellular carcinoma cell by downregulating ITGA1 expression. Int J Mol Sci 18: 514, 2017.

26. Chen X, Wang H, Liao HJ, Hu W, Gewin L, Mernaugh G, Zhang S, Zhang ZY, Vega-Montoto L, Vanacore RM, et al: Integrin-mediated type II TGF- $\beta$ receptor tyrosine dephosphorylation controls SMAD-dependent profibrotic signaling. J Clin Invest 124: 3295-3310, 2014 
27. Xia W, Lo CM, Poon RYC, Cheung TT, Chan ACY, Chen L, Yang S, Tsao GSW and Wang XQ: Smad inhibitor induces CSC differentiation for effective chemosensitization in cyclin D1and TGF- $\beta /$ Smad-regulated liver cancer stem cell-like cells. Oncotarget 8: 38811-38824, 2017.

28. Chen A, Beetham H, Black MA, Priya R, Telford BJ, Guest J, Wiggins GA, Godwin TD, Yap AS and Guilford PJ: E-cadherin loss alters cytoskeletal organization and adhesion in non-malignant breast cells but is insufficient to induce an epithelial-mesenchymal transition. BMC Cancer 14: 552, 2014

29. Gui GP, Wells CA, Browne PD, Yeomans P, Jordan S, Puddefoot JR, Vinson GP and Carpenter R: Integrin expression in primary breast cancer and its relation to axillary nodal status. Surgery 117: 102-108, 1995.
30. Gilhar A, Ullmann Y, Kalish RS, Berkutski T, Azizi E and Bank I: Favourable melanoma prognosis associated with the expression of the tumour necrosis factor receptor and the alphalbetal integrin: A preliminary report. Melanoma Res 7: 486-495, 1997.

31. Finn RS: Current and future treatment strategies for patients with advanced hepatocellular carcinoma: Role of mTOR inhibition. Liver Cancer 1: 247-256, 2012.

32. Ashworth RE and $\mathrm{Wu} \mathrm{J}$ : Mammalian target of rapamycin inhibition in hepatocellular carcinoma. World J Hepatol 6: 776-782, 2014.

33. Chen BW, Chen W, Liang H, Liu H, Liang C, Zhi X, Hu LQ, Yu XZ, Wei T, Ma T, et al: Inhibition of mTORC2 induces cell-cycle arrest and enhances the cytotoxicity of doxorubicin by suppressing MDR1 expression in HCC cells. Mol Cancer Ther 14: 1805-1815, 2015. 